\title{
Effects of Dietary Anaplerotic and Ketogenic Energy Sources on Renal Fatty Acid Oxidation Induced by Clofibrate in Suckling Neonatal Pigs
}

\author{
Xi Lin *, Brandon Pike, Jinan Zhao ${ }^{\dagger}$, Yu Fan $\ddagger$, Yongwen Zhu $§$, Yong Zhang ${ }^{\prime}$, Feng Wang \\ and Jack Odle \\ Laboratory of Developmental Nutrition, Department of Animal Sciences, North Carolina State University, \\ Raleigh, NC 27695, USA; bepike2@ncsu.edu (B.P.); jnzhao@zinpro.com (J.Z.); fanyucau@163.com (Y.F.); \\ zhuyw@scau.edu.cn (Y.Z.); yongzhang208@163.com (Y.Z.); fwang22@ncsu.edu (F.W.); jodle@ncsu.edu (J.O.) \\ * Correspondence: xilin@ncsu.edu; Tel.: +1-919-515-4014 \\ † Current Address: Sales Department, Zinpro Corporation, Eden Prairie, MN 55344, USA. \\ ‡ Current Address: College of Animal Science and Technology, China Agricultural University, \\ Beijing 100094, China. \\ $\S$ Current Address: Guangdong Provincial Key Laboratory of Animal Nutrition and Regulation, \\ College of Animal Science, South China Agricultural University, Guangzhou 510000, China. \\ || Current Address: College of Biological Engineering, Henan University of Technology, \\ Zhengzhou 450001, China.
}

Received: 25 November 2019; Accepted: 20 January 2020; Published: 22 January 2020

check for updates

\begin{abstract}
Maintaining an active fatty acid metabolism is important for renal growth, development, and health. We evaluated the effects of anaplerotic and ketogenic energy sources on fatty acid oxidation during stimulation with clofibrate, a pharmacologic peroxisome proliferator-activated receptor $\alpha$ $($ PPAR $\alpha)$ agonist. Suckling newborn pigs $(n=72)$ were assigned into 8 dietary treatments following a $2 \times 4$ factorial design: \pm clofibrate $(0.35 \%)$ and diets containing $5 \%$ of either $(1)$ glycerol-succinate (GlySuc), (2) tri-valerate (TriC5), (3) tri-hexanoate (TriC6), or (4) tri-2-methylpentanoate (Tri2MPA). Pigs were housed individually and fed the iso-caloric milk replacer diets for $5 \mathrm{~d}$. Renal fatty acid oxidation was measured in vitro in fresh tissue homogenates using $\left[1-{ }^{14} \mathrm{C}\right]$-labeled palmitic acid. The oxidation was $30 \%$ greater in pig received clofibrate and $25 \%$ greater $(p<0.05)$ in pigs fed the TriC6 diet compared to those fed diets with GlySuc, TriC5, and Tri2MPA. Addition of carnitine also stimulated the oxidation by twofold $(p<0.05)$. The effects of TriC6 and carnitine on palmitic acid oxidation were not altered by clofibrate stimulation. However, renal fatty acid composition was altered by clofibrate and Tri2MPA. In conclusion, modification of anaplerosis or ketogenesis via dietary substrates had no influence on in vitro renal palmitic acid oxidation induced by PPAR $\alpha$ activation.
\end{abstract}

Keywords: Renal fatty acid oxidation; anaplerotic and ketogenic energy; PPAR $\alpha$ activation

\section{Introduction}

The protective role of peroxisome proliferator-activated receptor $\alpha(\operatorname{PPAR} \alpha)$ activation in nephrosis induced by fatty acids [1,2] and chronic kidney disease (CKD) [3] recently has been drawing great attention. The nephrosis and CKD can also be identified in neonates with an epigenetic origin [4], and physiological aAlterations in the bioactive lipids pattern [5] and oxidative status have been observed in the abnormal lipid metabolism [6]. Therefore, understanding renal development and adaptation of energy metabolism is very important for human infant health. Fatty acids are the preferred renal energy substrate, and it is believed that maintaining an active fatty acid metabolism is significant for the renal protective effects afforded by PPAR $\alpha$ activation [2,7]. 
Activation of PPAR $\alpha$ by pharmaceutical agonists such as clofibrate has been studied extensively in the liver, but not in kidneys. A few studies revealed that clofibrate feeding increases total and antimycin-insensitive oxidation rates in the kidneys of rats [8], and PPAR $\alpha$-mediated mechanisms are involved in gene expression and regulation of mitochondrial and peroxisomal $\beta$-oxidation enzymes induced by dietary lipids in the renal cortex of suckling rats [9]. This indicates that PPAR $\alpha$ activation plays an important role in renal lipid metabolism. However, the enhancement of $\beta$-oxidation induced by clofibrate observed in rats usually is accompanied with peroxisome proliferation and hepatic carcinogenicity. Unlike rodent species, similar responses to clofibrate are not observed in the liver of humans or pigs $[10,11]$. Hence, the neonatal pig is commonly used as model for human pediatric nutrition and metabolism [12]. Recently we explored the effect of clofibrate on renal fatty acid oxidation in newborn pigs and confirmed that PPAR $\alpha$-mediated mechanisms are active [13]. Renal fatty acid oxidation in both mitochondria and peroxisomes was increased with oral administration of clofibrate (75 mg/kg body weight), and the natural developmental increase was greatly amplified [13]. The amplification induced by PPAR $\alpha$ signaling may have great significance for preventing the development of the free fatty acid-associated renal disease. In addition, the amplification could promote the postnatal energy supply and thermogenesis that are essential for renal development and the survival of neonatal piglets. However, it is not known whether the high renal fatty acid $\beta$-oxidation could be impacted by modifying the dietary energy source. Studies with liver indicate that the fatty acid oxidative rate could be affected by the status of anaplerosis and ketogenesis. For example, addition of malic acid [14] and 2-methylpentanoate (2MPA, unpublished data) in liver homogenates from pigs and rats increased the fatty acid oxidation in vitro and modified the carbon distribution between $\mathrm{CO}_{2}$ and acid soluble products (ASP). The gene mitochondrial 3-hydroxy-3-methyl-glutaryl-CoA synthase ( $m H M G C S)$, coding for the key enzyme of ketogenesis is expressed significantly in liver and kidney after feeding clofibrate, but the ketone body levels in plasma and tissues remain low $[13,15]$. Because the excess acetyl-CoA generated from the elevated fatty acid $\beta$-oxidation needs to divert into the citric acid cycle (CAC) and the ketogenic pathway for further metabolism, the capacities of these pathways are critical for maintaining a high $\beta$-oxidative flux.

Renal energy metabolism is rather immature at birth, although fatty acids are the preferred energy substrate. The development of oxidative metabolism is progressive through the suckling period, in which PPAR $\alpha$ activation is recognized as essential for fatty acid uptake, transport, and utilization. To maintain the efficacy of PPAR $\alpha$ activation of renal lipid oxidative metabolism, in this study, we examined the roles of CAC anaplerosis and ketogenesis during elevated fatty acid oxidation by supplementation of extra anaplerotic carbon sources and ketogenic fatty acids such as medium-chain fatty acids (MCFA, [16]). MCFA were chosen because MCFA are absorbed quickly and oxidized in the mitochondria with no need of carnitine palmitoyl-transferase I (CPT I) transfer. Accordingly, MCFA are more ketogenic than long-chain fatty acids, and they have been used in ketogenic diets extensively. In addition, 2MPA (a branched-chain MCFA), valerate (an odd-chain MCFA), and hexanoate (an even-chain MCFA) were supplemented as triglycerides in the diets of this study. Among the MCFA, 2-MPA is a novel source of anaplerotic carbon via the propionyl-CoA/succinyl-CoA pathway, valerate is a dual source of both anaplerotic and ketogenic carbon via producing propionyl-CoA and acetyl-CoA and hexanoate is ketogenic via production of acetyl-CoA and acetoacetyl-CoA. Furthermore, succinate, an intermediate of the CAC, was used as a direct anaplerotic carbon source due to its potential inactivation of mHMGCS via succinyl-CoA [17]. We hypothesized that modification of the capacities of the CAC and ketogenic pathways affects the elevated fatty acid oxidative flux induced by supplementation of clofibrate in milk $(0.35 \%$ of dry matter) and alters the distribution of the fatty acid oxidative metabolites for renal energy generation. The data obtained from this study would be useful in understanding the role of dietary energy source in fatty acid oxidation induced by PPAR $\alpha$ activation in the kidney during early development. 


\section{Results}

\subsection{Animal Growth Performance}

There were no effects of supplementation of clofibrate or dietary addition of $5 \%$ glycerol + succinate (GlySuc), triglycerides of valeric acid (TriC5), hexanoic acid (TriC6), and 2MPA (Tri2MPA) on piglet growth performance $(p>0.1)$. The overall piglet daily gains, liquid diet intakes, and final body weights were $120 \pm 11 \mathrm{~g}$, $780 \pm 23 \mathrm{~g}$, and $2.0 \pm 0.07 \mathrm{~kg}$, respectively. Supplementation of clofibrate into the milk replacer also had no effects on kidney weight or protein concentration. The average kidney weight was $8.1 \pm 0.3 \mathrm{~g}$, and kidney protein concentration was $33.9 \pm 1.4 \mathrm{mg} / \mathrm{g}$ of fresh tissue.

\subsection{Renal Fatty Acid Profile}

No interaction was observed between clofibrate and dietary treatment for each fatty acid $(p>0.05)$. The main effects of clofibrate and the dietary treatment were reported in Table 1 . Dietary supplementation of clofibrate increased renal fatty acid concentrations ( $\mu \mathrm{g} / 100 \mathrm{mg}$ tissue) of C16:1 n9, C18:1 n9 $(p<0.04)$ and C18:3 n3 and C18:3 n6 $(p<0.01)$ but decreased in C22:6 n3 ( $p<0.01)$ (Table 1). Addition of Tri2MPA to the diet increased concentrations of C15:0, but decreased C18:2 n6, C20:2 n7, and C20:3 n6 ( $p<0.02)$ compared with other dietary additions (GlySuc, TriC5, and TriC6). Generally, clofibrate increased mono fatty acids and dietary Tri2MPA decreased polyunsaturated fatty acids $(p<0.05)$. Clofibrate had no impact on the total fatty acid, while dietary Tri2MPA reduced the total fatty acids. No clofibrate or dietary treatment had an impact on n6/n3 fatty acid ratio.

Table 1. Effect of clofibrate and medium-chain triglycerides on renal fatty acid composition.

\begin{tabular}{|c|c|c|c|c|c|c|c|c|c|c|c|}
\hline \multirow[b]{3}{*}{ FA } & \multicolumn{10}{|c|}{ Main Effects $@$} & \multirow[b]{3}{*}{$p-\mathrm{V}$} \\
\hline & \multicolumn{5}{|c|}{ Clofibrate } & \multicolumn{5}{|c|}{ Medium-Chain Fatty Acid } & \\
\hline & $\mathrm{NB}^{+}$ & Clof- & Clo+ & SEM & $p-\mathrm{V}$ & GlySuc & TriC5 & TriC6 & Tri2MPA & SEM & \\
\hline \multicolumn{12}{|c|}{$\mu g / 100 m g$ Tissue } \\
\hline C14:0 & 2.49 & 0.46 & 0.89 & 0.18 & 0.087 & 0.48 & 0.81 & 0.90 & 0.52 & 0.25 & 0.538 \\
\hline C15:0 & 1.26 & 0.25 & 0.37 & 0.06 & 0.201 & $0.09^{a}$ & $0.38^{b}$ & $0.11^{\mathrm{a}}$ & $0.68^{c}$ & 0.08 & 0.001 \\
\hline C16:0 & 149 & 122 & 123 & 47.0 & 0.742 & 127 & 124 & 132 & 108 & 6.56 & 0.081 \\
\hline C16:1n9 & 14.5 & 2.79 & $4.72 *$ & 0.50 & 0.001 & 3.17 & 4.41 & 3.94 & 3.40 & 0.71 & 0.605 \\
\hline C17:1 & 0.68 & 0.38 & 0.46 & 0.10 & 0.637 & 0.23 & 0.39 & 0.42 & 0.60 & 0.14 & 0.288 \\
\hline C18:0 & 93.3 & 102 & 95.5 & 3.19 & 0.834 & 99.3 & 99.5 & 103 & 94.0 & 4.59 & 0.533 \\
\hline C18:1n9 & 175 & 113 & $136 *$ & 7.00 & 0.041 & 102 & 125 & 137 & 132 & 9.84 & 0.087 \\
\hline C18:2n6 & 64.2 & 117 & 132 & 6.39 & 0.101 & $140^{b}$ & $127^{b}$ & $136^{b}$ & $92.5^{a}$ & 8.96 & 0.002 \\
\hline C18:3n6 & 0.63 & 0.46 & $0.71 *$ & 0.06 & 0.005 & 0.53 & 0.58 & 0.49 & 0.73 & 0.09 & 0.228 \\
\hline $\mathrm{C} 18: 3 \mathrm{n} 3$ & 0.36 & 2.20 & 3.06 * & 0.23 & 0.013 & 3.16 & 2.82 & 2.07 & 2.48 & 0.34 & 0.124 \\
\hline C20:0 & 4.46 & 3.91 & 3.74 & 0.19 & 0.570 & 3.88 & 3.80 & 3.80 & 3.85 & 0.28 & 0.995 \\
\hline C20:1n9 & 1.98 & 0.83 & 0.96 & 0.06 & 0.190 & 1.02 & 0.98 & 0.86 & 0.71 & 0.09 & 0.091 \\
\hline C20:2n7 & 6.90 & 6.02 & 6.58 & 0.45 & 0.481 & $7.76^{b}$ & $6.63^{a b}$ & $6.17^{\mathrm{ab}}$ & $4.84^{\mathrm{a}}$ & 0.07 & 0.022 \\
\hline C20:3n6 & 6.81 & 4.65 & 5.54 & 0.35 & 0.091 & $4.70^{a b}$ & $5.88^{b}$ & $5.78^{b}$ & $3.97^{\mathrm{a}}$ & 0.06 & 0.028 \\
\hline C20:4n6 & 155 & 120 & 106 & 5.55 & 0.088 & 115 & 120 & 117 & 100 & 8.12 & 0.303 \\
\hline C20:3n3 & 0.48 & 3.20 & 2.50 & 0.48 & 0.168 & 2.99 & 2.45 & 3.86 & 2.09 & 0.68 & 0.292 \\
\hline C20:5n3 & 1.28 & 1.52 & 1.75 & 0.11 & 0.223 & 1.53 & 1.68 & 1.80 & 1.47 & 0.16 & 0.492 \\
\hline C22:0 & 3.51 & 4.20 & 3.67 & 0.20 & 0.068 & 4.10 & 4.02 & 3.97 & 3.67 & 0.28 & 0.953 \\
\hline C22:1n9 & 0.30 & 0.26 & 0.30 & 0.07 & 0.709 & 0.31 & 0.38 & 0.22 & 0.19 & 0.09 & 0.516 \\
\hline C22:2 & 0.29 & 0.36 & 0.43 & 0.07 & 0.508 & 0.55 & 0.36 & 0.21 & 0.46 & 0.09 & 0.079 \\
\hline C23:0 & 1.62 & 1.50 & 1.76 & 0.15 & 0.298 & 1.46 & 1.50 & 1.62 & 1.88 & 0.24 & 0.494 \\
\hline C22:5n3 & 11.8 & 7.94 & 8.54 & 0.55 & 0.388 & 8.83 & 8.30 & 8.08 & 7.36 & 0.78 & 0.342 \\
\hline C24:0 & 4.43 & 5.74 & 5.58 & 0.28 & 0.662 & $6.14^{\mathrm{b}}$ & $5.85^{b}$ & $6.03^{b}$ & $4.56^{\mathrm{a}}$ & 0.39 & 0.022 \\
\hline C22:6n3 & 8.35 & 10.6 & $8.13 *$ & 0.66 & 0.009 & 9.94 & 10.0 & 9.55 & 7.87 & 0.93 & 0.324 \\
\hline C24:1 & 10.3 & 8.89 & 8.10 & 0.54 & 0.260 & 8.84 & 9.22 & 8.80 & 6.95 & 0.77 & 0.164 \\
\hline Sum & 789 & 697 & 722 & 21.1 & 0.424 & $731^{b}$ & $732^{b}$ & $759^{b}$ & $617^{a}$ & 30.3 & 0.009 \\
\hline MUFA & 203 & 127 & $149^{*}$ & 7.46 & 0.043 & 139 & 151 & 145 & 114 & 10.8 & 0.080 \\
\hline
\end{tabular}


Table 1. Cont.

\begin{tabular}{|c|c|c|c|c|c|c|c|c|c|c|c|}
\hline \multirow[b]{3}{*}{ FA } & \multicolumn{10}{|c|}{ Main Effects ${ }^{@}$} & \multirow[b]{3}{*}{$p-\mathrm{V}$} \\
\hline & \multicolumn{5}{|c|}{ Clofibrate } & \multicolumn{5}{|c|}{ Medium-Chain Fatty Acid } & \\
\hline & $\mathrm{NB}^{+}$ & Clof- & Clo+ & SEM & $p-\mathrm{V}$ & GlySuc & TriC5 & TriC6 & Tri2MPA & SEM & \\
\hline \multicolumn{12}{|c|}{$\mu g / 100 \mathrm{mg}$ Tissue } \\
\hline PUFA & 255 & 275 & 274 & 11.3 & 0.964 & $296^{\mathrm{b}}$ & $286^{b}$ & $291^{b}$ & $223^{a}$ & 16.6 & 0.009 \\
\hline FAn3 & 21.2 & 25.6 & 23.7 & 1.56 & 0.774 & 26.5 & 25.3 & 25.4 & 21.3 & 2.24 & 0.343 \\
\hline FAn6 & 227 & 243 & 243 & 10.1 & 0.971 & $260^{b}$ & $253^{b}$ & $259^{b}$ & $197^{\mathrm{a}}$ & 14.6 & 0.008 \\
\hline Fan6/n3 & 11.5 & 10.5 & 10.9 & 0.55 & 0.556 & 10.6 & 10.9 & 11.2 & 10.1 & 0.81 & 0.447 \\
\hline
\end{tabular}

${ }^{\circledR}$ No interaction was detected between clofibrate and dietary medium-chain fatty acid effects. Tabulated data represent least square means and standard error of the means for the main effects (clofibrate effect: $n=32$; medium-chain fatty acid effect: $n=16$ ). ${ }^{*}$ Least square means under the main effect of clofibrate within a row differ $(p<0.05)$; Clof-: all pigs received milk with no clofibrate supplementation and Clof + : all pigs received milk with clofibrate supplementation. ${ }^{a, b, c}$ Least square means under the main effect of medium-chain fatty acid within a row lacking a common superscript differ $(p<0.05)$; GlySuc: glycine + succinate, TriC5: triglyceride of valerate, TriC6: triglyceride of hexanoate and Tri2MPA: triglyceride of 2 -methylpentanoate. ${ }^{\dagger}$ Newborn (NB) concentrations of C14:0, C15:0, C16:1n9, C20:5n3, C20:1n9 C18:3n3, and C20:3n3 are different from 5-d old pigs $(p<0.05)$.

\subsection{Renal $\beta$-hydroxybutyrate and Acetate Concentrations}

Supplementation of clofibrate had no detectable effect on renal $\beta$-hydroxybutyrate $(p=0.1)$ or acetate concentrations. However, the concentration of $\beta$-hydroxybutyrate was higher in kidney tissue from pigs fed Tri2MPA and TriC6 than in controls fed GlySuc $(p<0.02)$. No interactions between clofibrate and other dietary treatments $(p=0.6)$ were detected in $\beta$-hydroxybutyrate. There were no effects of clofibrate supplementation or dietary energy treatments on the renal acetate concentration, but the concentration of acetate was 112-fold higher than $\beta$-hydroxybutyrate (Table 2).

Table 2. Concentrations of $\beta$-hydroxybutyrate and acetate in kidney tissue.

\begin{tabular}{|c|c|c|c|c|}
\hline \multirow[b]{2}{*}{ Main Effects @ } & \multicolumn{2}{|c|}{$\beta$-Hydroxybutyrate } & \multicolumn{2}{|c|}{ Acetate } \\
\hline & LSmean & SEM & LSmean & SEM \\
\hline & \multicolumn{2}{|c|}{$\mu \mathrm{mol} / \mathrm{g}$ Tissue } & \multicolumn{2}{|c|}{$\mu \mathrm{mol} / \mathrm{g}$ Tissue } \\
\hline \multicolumn{5}{|l|}{ Clofibrate $^{+}$} \\
\hline Clof- & 1.68 & 0.12 & 197 & 23.8 \\
\hline Clof + & 1.94 & 0.12 & 210 & 24.7 \\
\hline$p$-Value & 0.13 & & 0.70 & \\
\hline \multicolumn{5}{|c|}{ Dietary medium-chain fatty acid* } \\
\hline GlySuc & $1.42^{\mathrm{a}}$ & 0.17 & 194 & 35.1 \\
\hline TriC5 & $1.78^{\mathrm{ab}}$ & 0.17 & 224 & 37.5 \\
\hline TriC6 & $1.89^{b}$ & 0.16 & 204 & 32.1 \\
\hline Tri2MPA & $2.14^{\mathrm{b}}$ & 0.16 & 192 & 32.1 \\
\hline$p$-Value & 0.023 & & 0.91 & \\
\hline
\end{tabular}

\footnotetext{
${ }^{\circledR}$ No interaction was detected between clofibrate and dietary medium-chain fatty acid. The main effects of clofibrate and dietary medium-chain fatty acid were reported. ${ }^{\dagger}$ The main effect of clofibrate $(n=28)$, Clof-: all pigs received milk with no clofibrate supplementation and Clof + : all pigs received milk with clofibrate supplementation. * The main effect of dietary medium-chain fatty acid $(n=16)$. GlySuc: glycine + succinate, TriC5: triglyceride of valerate, TriC6: triglyceride of hexanoate and Tri2MPA: triglyceride of 2-methylpentanoate. Tabulated data represent least square means (LSmean) and standard error of means (SEM). ${ }^{\mathrm{a}, \mathrm{b}}$ Least square means under the main effect within column lacking a common superscript differ $(p<0.05)$.
}

\subsection{Renal Palmitic Acid Oxidation}

No interactions were detected between clofibrate and other dietary treatments (GlySuc, TriC5, TriC6, and Tri2MPA) for palmitic acid oxidation ( $p \geq 0.1)$. Supplementation of clofibrate in the milk replacer increased palmitic acid oxidation $(p<0.0001)$. The ${ }^{14} \mathrm{C}$ accumulations (nmol/(h.mg fresh tissue 
protein)) in $\mathrm{CO}_{2}$, ASP, and $\mathrm{CO}_{2}+$ ASP were 31,28 , and $30 \%$ higher in kidney from pigs fed the diets with clofibrate than without clofibrate (Figure 1).

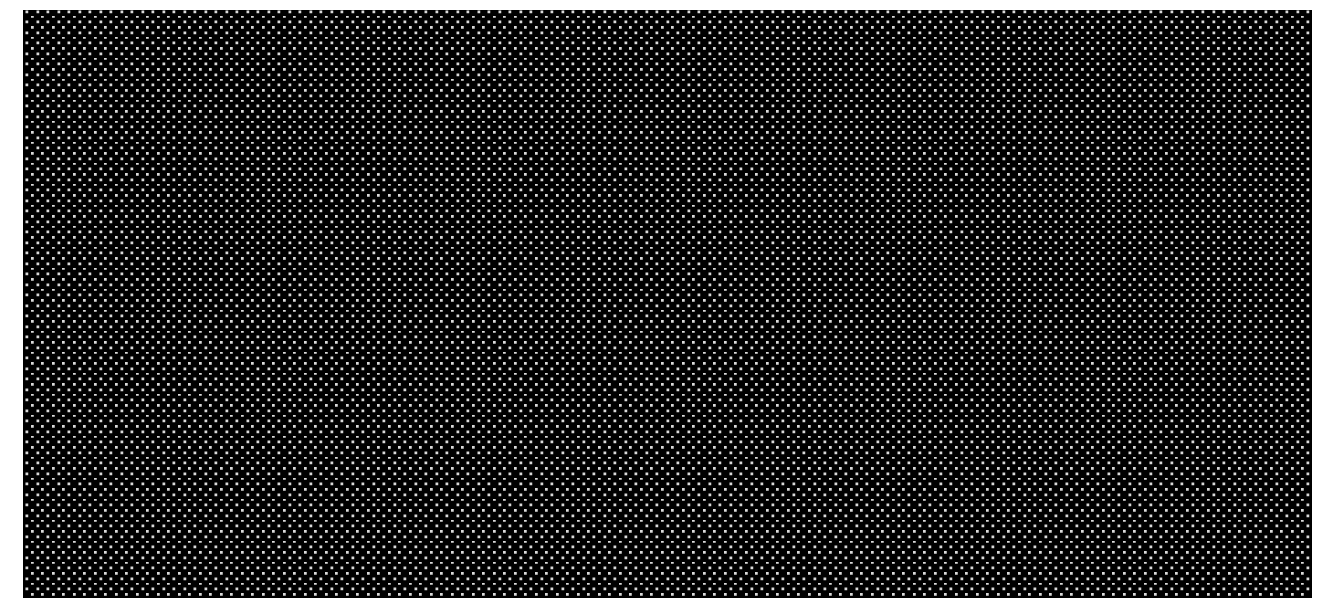

Figure 1. The main effect of clofibrate on palmitic acid oxidation. Data (Lsmeans \pm SEM) are ${ }^{14} \mathrm{C}$-accumulations in $\mathrm{CO}_{2}$, acid soluble products (ASP) and $\mathrm{CO}_{2}+\mathrm{ASP}(n=32)$. ${ }^{\text {abc }}$ Treatments (newborn, clof- (no clofibrate supplementation) and clof+ (clofibrate supplementation) for $\mathrm{CO}_{2}$, ASP and $\mathrm{CO}_{2}+\mathrm{ASP}$ with different superscripts differ $(p<0.05)$.

Supplementation of TriC6 in the milk replacer also increased the palmitic acid oxidation $(p<0.001)$. The ${ }^{14} \mathrm{C}$ accumulations (nmol/(h.mg fresh tissue protein)) on average in $\mathrm{CO}_{2}, \mathrm{ASP}$, and $\mathrm{CO}_{2}+\mathrm{ASP}$ were $25 \%, 24 \%$, and $25 \%$ higher in kidney from pigs fed the diet with TriC 6 than the diets with GlySuc, TriC5, and Tri2MPA (Figure 2).

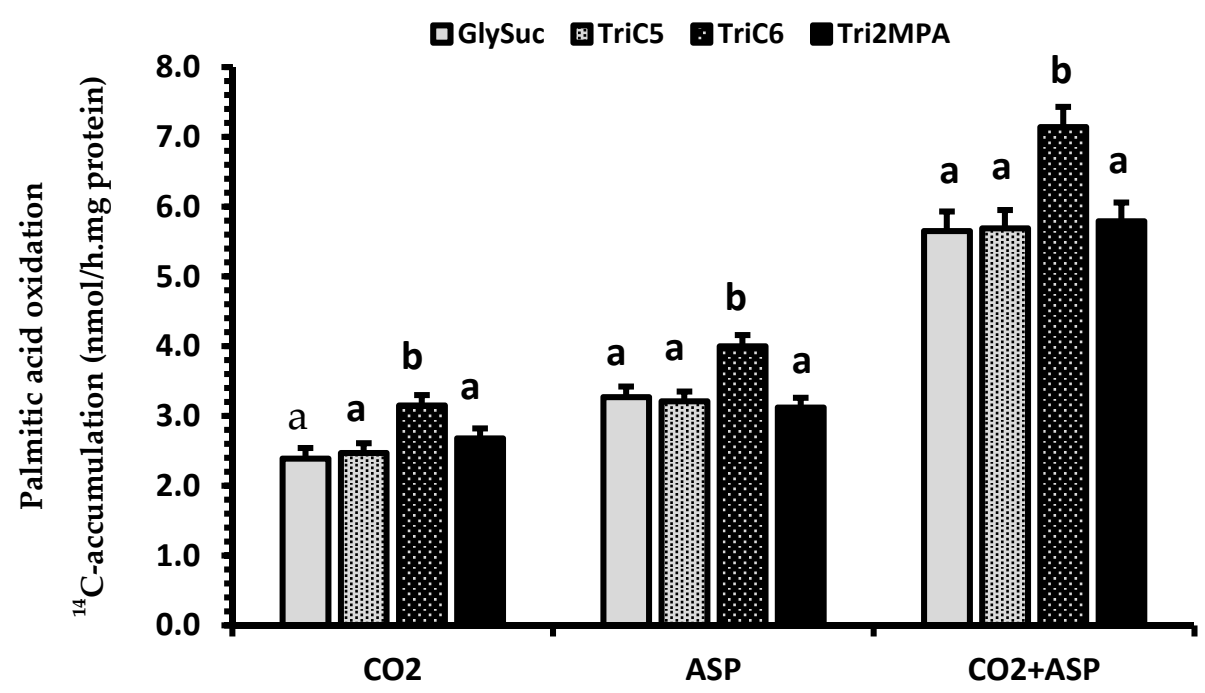

Figure 2. The main effect of dietary treatments on $\left[1-{ }^{14} \mathrm{C}\right]$-palmitic acid oxidation. GlySuc (diet supplement with glycerol and succinate), TriC5 (triglyceride of valerate), TriC6 (triglyceride of hexanoate), and Tri2MPA (triglyceride of 2MPA). Data (Lsmeans \pm SEM) are ${ }^{14} \mathrm{C}$-accumulations in $\mathrm{CO}_{2}$, acid soluble products (ASP) and $\mathrm{CO}_{2}+\mathrm{ASP}(n=16) .{ }^{\mathrm{a}, \mathrm{b}}$ Treatments for $\mathrm{CO}_{2}, \mathrm{ASP}$, and $\mathrm{CO}_{2}+\mathrm{ASP}$ with different superscripts differ $(p<0.05)$.

There were no interactions between clofibrate/dietary treatment and the factors (carnitine, iodoacetamide, and L659699) added in vitro incubation medium $(p>0.47)$, and the effects of the factors on palmitic acid oxidation were reported in Figure 3. Addition of carnitine to the oxidation medium in vitro increased the renal palmitic acid oxidation $(p<0.0001)$. The ${ }^{14} \mathrm{C}$ accumulations (nmol/(h.mg fresh tissue protein)) on average in $\mathrm{CO}_{2}, \mathrm{ASP}$, and $\mathrm{CO}_{2}+\mathrm{ASP}$ were $74 \%, 128 \%$, and $102 \%$ greater 
from carnitine than control and L659699 or iodoacetamide, the inhibitors of ketogenesis (Figure 3A). Supplementation of carnitine also changed the distribution (\%) between $\mathrm{CO}_{2}$ and $\mathrm{ASP}$, reducing ${ }^{14} \mathrm{C}$ accumulation in $\mathrm{CO}_{2}$ by $16 \%$ and increasing that in ASP by 13\% (Figure 3B). Neither L659699 nor iodoacetamide had an effect on oxidation $(p>0.1)$. Additionally, the ${ }^{14} \mathrm{C}$ accumulations (nmol/(h.mg fresh tissue protein)) in $\mathrm{CO}_{2}, \mathrm{ASP}$, and $\mathrm{CO}_{2}+\mathrm{ASP}$ from 5-day old pigs were greater than newborn pigs $(p<0.001)$, regardless of treatment. However, age did not alter the distribution between $\mathrm{CO}_{2}$ and ASP (data not shown).

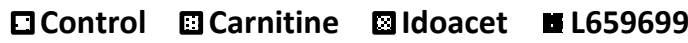
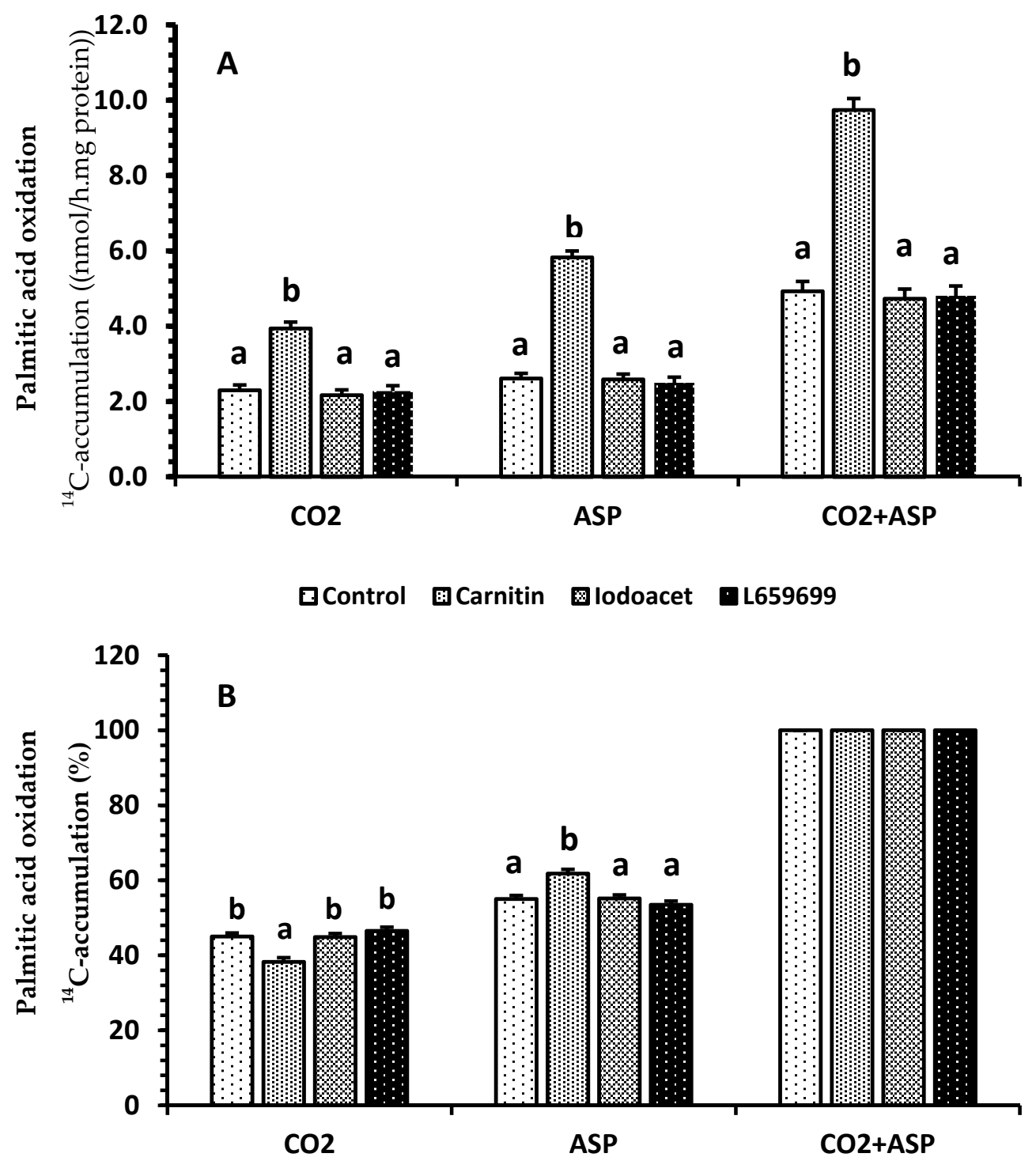

Figure 3. The main effect of carnitine and inhibitors of 3-hydroxy-3-methyl-glutaryl-CoA synthase (HMGCS) and acetoacetyl-CoA deacylase (AACD) on palmitic acid oxidation. Fresh kidney homogenates were incubated with palmitic acid only (control), and carnitine, iodoacetamide (Idoacet), or L659699. Data in A (Lsmeans \pm SEM) are ${ }^{14} \mathrm{C}$-accumulations in $\mathrm{CO}_{2}$, acid soluble products (ASP), and $\mathrm{CO}_{2}+\mathrm{ASP}(n=16)$. Data in $\mathrm{B}$ (Lsmeans \pm SEM) are the percentage of the ${ }^{14} \mathrm{C}$-accumulations in $\mathrm{CO}_{2}$, acid soluble products (ASP), and $\mathrm{CO}_{2}+\mathrm{ASP}(n=16) .{ }^{\mathrm{a}, \mathrm{b}}$ Treatments in $(\mathbf{A})$ and $(\mathbf{B})$ for $\mathrm{CO}_{2}, \mathrm{ASP}$, and $\mathrm{CO}_{2}+\mathrm{ASP}$ with different superscripts differ $(p<0.05)$. 


\subsection{Enzyme Activity}

There was an interaction between clofibrate and dietary treatments $(p<0.002)$ for citrate synthase activity (Figure 4A). Supplementation of clofibrate increased the citrate synthase activity in pigs fed GlySuc $(p<0.004)$, but no difference was detected among all other dietary treatment groups $(p \geq 0.1)$. The activity of citrate synthase was on average 2.5-fold higher from $5 \mathrm{~d}$-old pigs than newborn pigs. An interaction between clofibrate and the dietary treatment $(p<0.04)$ was also observed for propionyl-CoA carboxylase (Figure 4B).

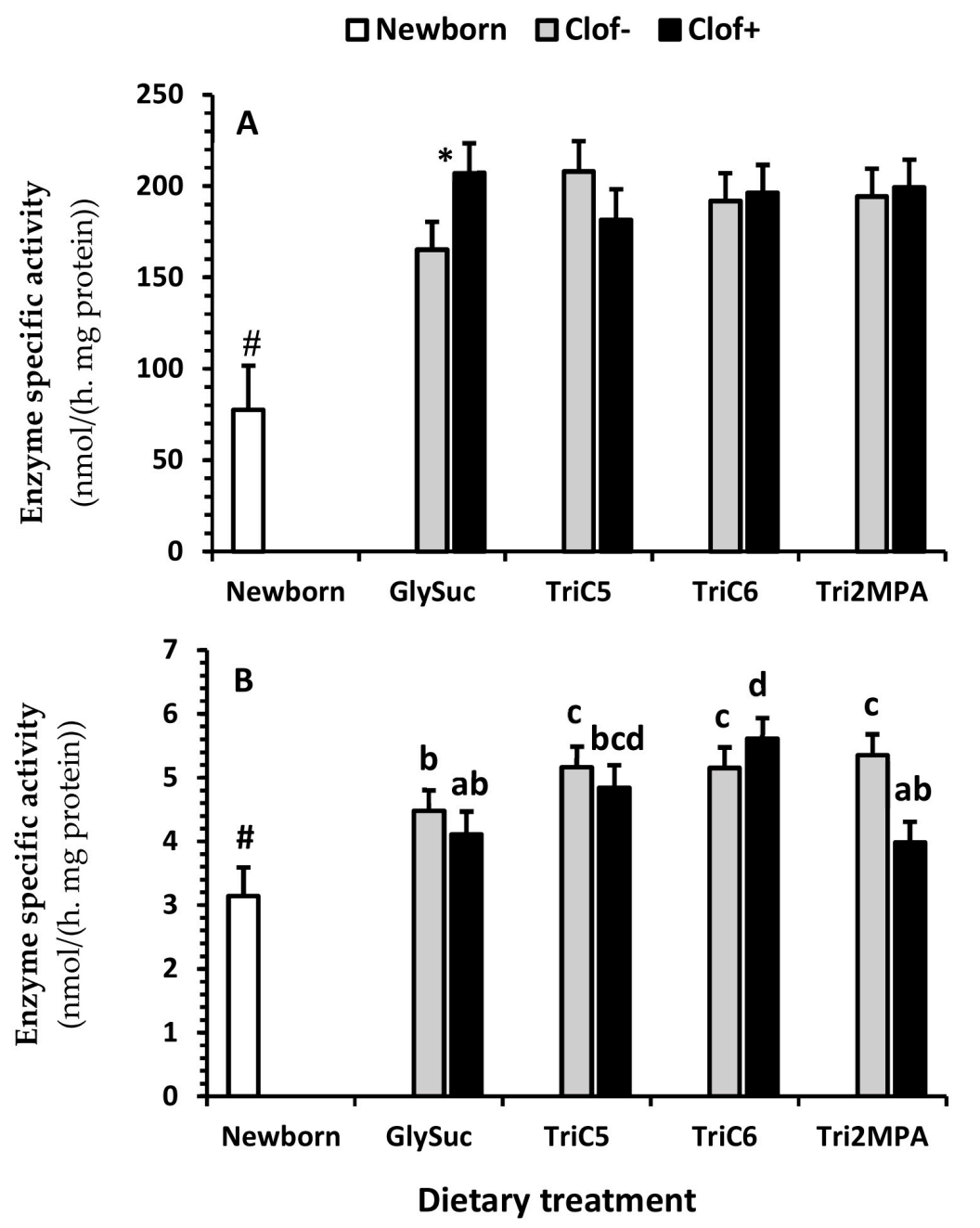

Figure 4. The effect of clofibrate and dietary treatments on citrate synthase and propionyl-CoA carboxylase activity. Data (Lsmeans \pm SEM) are specific activities (nmol/(h.mg of tissue protein)); $n=16) .{ }^{*}$ indicates difference in (A) between pigs fed GlySuc with and without clofibrate $(p<0.004)$. $\mathrm{a}, \mathrm{b}, \mathrm{c}, \mathrm{d}$ Treatments cross columns in (B) with different superscripts differ $(p<0.05)$. ${ }^{\text {\# }}$ indicate difference in $(\mathbf{A}, \mathbf{B})$ between newborn and 5 d-old pigs $(p<0.05)$.

Supplementation of clofibrate had no significant influence on the propionyl-CoA carboxylase activity $(p=0.1)$, but increased the enzyme activity in pigs fed TriC6 compared to pigs fed GlySuc $(p<0.02)$, and decreased activity in pigs fed Tri2MPA compared to those fed TriC6 $(p<0.02)$. The activity of propionyl-CoA carboxylase (Figure $4 \mathrm{~B}$ ) was on average 1.5-fold higher from $5 \mathrm{~d}$-old pigs than newborn pigs $(p<0.0075)$.

No interaction between clofibrate and the dietary treatment was detected $(p>0.05)$ for acetyl-CoA carboxylase (Figure 5). Supplementation of neither clofibrate nor the MCFA had an effect on the activity 
of acetyl-CoA carboxylase $(p=0.09)$. The activity of acetyl-CoA carboxylase (Figure 5 ) was on average 3.7 -fold greater from $5 \mathrm{~d}$-old pigs than newborn pigs $(p<0.04)$.

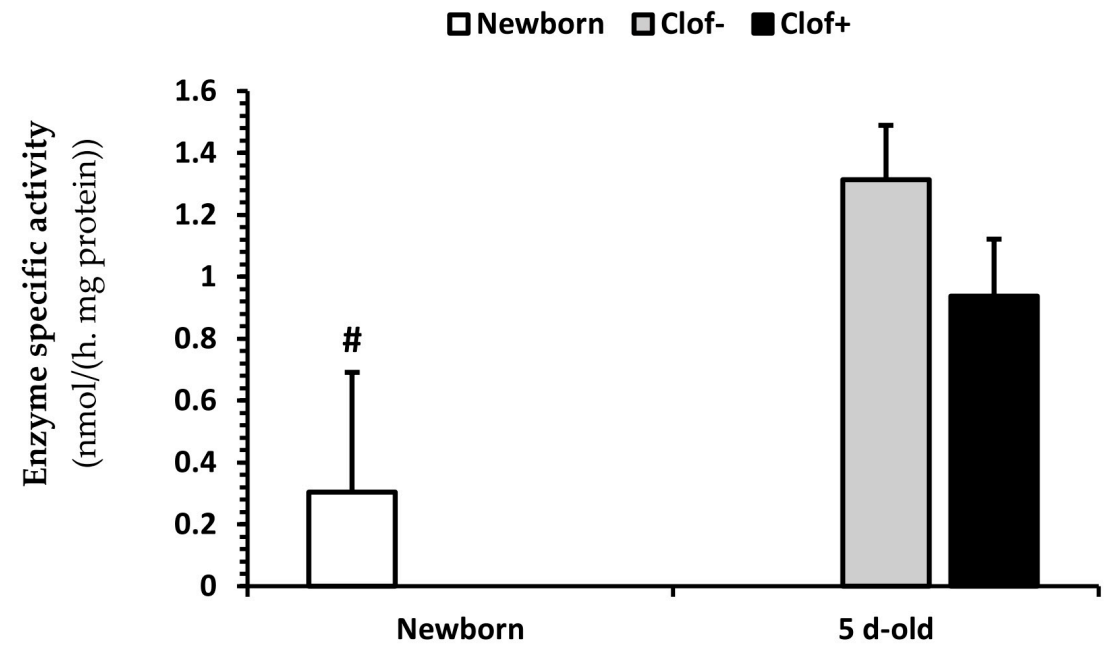

Figure 5. The effect of dietary clofibrate fed to pigs for five days on acetyl-CoA carboxylase activity. Data (Lsmeans \pm SE) are specific activities (nmol/(h.mg of tissue protein)). No significant difference was observed between pigs with and without clofibrate $(p=0.06)$. \# The enzyme activity was on average 3.7 -fold greater from 5 d-old pigs than newborn pigs $(p<0.04)$.

\subsection{Gene Expression}

There were no effects of clofibrate and dietary treatments on the abundance of genes associated with renal fatty acid metabolism (PPAR $\alpha, M C D, K C O A, P G C 1 \alpha, F G F 21, M C A D, L C A D$, and VLCAD) measured in this study $(p \geq 0.11$; Table S1).

\section{Discussion}

Limited studies have examined the developmental aspects of renal fatty acid oxidation. Palmitic acid oxidation by neonatal kidney from rats increased after birth and reached a maximum between 5 and 7 days of postnatal life [18]. Consistent with these results, palmitic acid oxidation in our study showed a 1.9-fold higher rate in $5 \mathrm{~d}$-old pigs than in newborn pigs. Moreover, the developmental increase could be amplified further by addition of clofibrate into the milk diet, without altering kidney size (weight) or growth performance of the piglets. Similar results were observed from sow-raised pigs receiving an oral gavage of clofibrate in our previous study [13]. In that study, the amplified $\beta$-oxidation was associated with an induction of gene expression and activity of carnitine palmitoyl-transferase I (CPTI), one of the target genes of PPAR $\alpha$ [13]. The increased CPTI activity was accompanied by a rapid reduction in the sensitivity of CPTI and an increase in the gene expression of malonyl-CoA decarboxylase $(M C D)$ in the liver of swine [15], suggesting that malonyl-CoA is involved in the regulation of fatty acid catabolism induced by clofibrate. Unlike in the liver, however, the effects of clofibrate on MCD was not detected in the kidneys in this study. In addition to CPTI, the effects of clofibrate on expression of genes PGC1 $\alpha$, $M C A D, L C A D$, and $V L C A D$ with increased PPAR $\alpha$ were reported in the nephrotic kidney [2] in rats. However, the expressions of these genes were not significantly different between pigs with and without administration of clofibrate in this study. The physiological status and response of species to clofibrate administration could be factors for the variations, and apparently need to be further investigated.

The induction of renal fatty acid oxidation via activation of PPAR $\alpha$ occurred with the same pattern as observed in the liver of neonatal pigs [19]. Although renal $\beta$-oxidation was increased as previously observed [13], the increase had a minimal impact on ketogenesis probably due to a limited activity of HMGCS, owing to a posttranscriptional defect described in pigs [20]. Because of the diminished ketogenesis observed in neonatal pigs [21], we have been interested in the effects of modifying CAC 
anaplerosis and ketogenesis on fatty acid utilization, especially when $\beta$-oxidation is induced by PPAR $\alpha$ activation. In this study, hexanoic acid was used as a source of ketogenic carbon for both mHMGCS and acetoacetyl-CoA deacylase (AACD) pathways via acetyl-CoA or/and acetoacetyl-CoA. In contrast, 2MPA was selected as a novel source of anaplerotic carbon via the propionyl-CoA-succinyl-CoA pathway and valeric acid was used as a dual source of both anaplerotic and ketogenic carbon via its production of both propionyl-CoA and acetyl-CoA from $\beta$-oxidation. The CAC intermediate, succinate, was used as a direct anaplerotic carbon source and also due to its role in inhibition of ketogenesis by inactivation of mHMGCS via succinyl-CoA [17]. Although the activity of mHMGCS could not be improved by induction of the gene expression via activation of PPAR $\alpha$ [15], we expected that ketone bodies might be produced via the AACD pathway when fatty acid $\beta$-oxidation is increased. Indeed, feeding diets containing MCFA increased $\beta$-hydroxybutyrate concentration as compared to succinate in kidney tissues, suggesting that the renal ketogenic pathways could be modified by diet. However, the modification was not associated with clofibrate because no interaction with dietary energy sources was detected. Furthermore, the modification of ketogenesis by dietary MCFA might not be due to a change in CAC cataplerosis activity, because there was no difference between the even, odd, and branched-MCFA. Thus, the increase in renal $\beta$-hydroxybutyrate from dietary MCFA could be due to an increase in citrate synthase and a relative decrease in $\beta$-hydroxybutyrate from dietary succinate, in which the mHMGCS could be inactivated by succinyl-CoA derived from succinate [17].

Although dietary TriC6 and Tri2MPA increased renal $\beta$-hydroxybutyrate as compared to the diet containing succinate, palmitic acid oxidation increased only in pigs that received the diet containing TriC6. No evidence of anaplerotic effects on $\beta$-oxidation were observed in pigs fed GlySuc, TriC5, and Tri2MPA treatments. Furthermore, the enzyme activity of propionyl-CoA carboxylase was unaltered by these treatments. The interaction between anaplerotic and cataplerotic reactions was studied in human kidney during prolonged starvation [22]. A balance of anaplerotic reactions to replenish the $\alpha$-ketoglutarate in the CAC and cataplerotic reactions to drain remnant 4-carbon metabolic intermediates from the cycle for glucose synthesis is essential and required of the renal tissue during starvation [23,24]. This suggests that entry and removal of intermediates into or out of the CAC, as in the fasted kidney, were likely balanced in our study. Thus, the effect of anaplerotic carbon on fatty acid oxidation might not be detected in vitro in the limited tissue homogenates of our study. However, the stimulatory impact of TriC6 on palmitic acid oxidation was unexpected. We speculate that it could be due to the regulatory role of acetyl-CoA (as a positive allosteric regulator) in the archetypical anaplerotic enzyme, pyruvate carboxylase [24], and potentially a more available free CoA pool in the kidney tissues from piglets fed diet with TriC6. Compared with propionyl-CoA, acetyl-CoA releases $\mathrm{CoA}$ and acetate via acetyl-CoA deacylase, while reversibility of methylmalonyl-CoA generated from propionyl-CoA would be reduced when propionyl-CoA is increased [25]. In addition, supplementation of inhibitors of the ketogenesis pathways had no effect on the palmitic acid oxidation and its oxidative metabolite distribution between $\mathrm{CO}_{2}$ and ASP, suggesting that renal ketogenesis (similar to piglet liver) is negligible from either mHMGCS or AACD. In support of this, the acetate measured in kidney was over 100 times higher than $\beta$-hydroxybutyrate. This is consistent with our previous findings in liver, with acetate being the predominant metabolic product of fatty acid oxidation [14] in neonatal pigs. The physiological role of acetate in mitochondria has not been stressed to an adequate extent, however, the CoA required for maintaining $\beta$-oxidation rate would be released by generating acetate from the acetyl-CoA. An increase in acetate has been observed in vitro under conditions of high fatty acid oxidation [14].

Feeding clofibrate had a profound impact on cardiac fatty acid composition in rats [26], but the impact on renal fatty acid composition has not been studied in pigs, rodents, or any other species. Clofibrate significantly reduced the $\mathrm{n} 6 / \mathrm{n} 3$ fatty acid ratio in the hearts of rats by decreasing linoleic acid (C18:2 n6) and arachidonic acid (C20:4 n6), which was highly associated with the animals' lipid peroxidation status [26]. We found that clofibrate significantly increased total monounsaturated fatty acid and $\alpha$ - and $\gamma$-Linolenic acid (C18:3 n3 and n6) and reduced docosahexaenoic acid (C22:6 n3). 
However, the alternations of these fatty acids had no impact on the n6/n3 ratio, suggesting that effect of clofibrate on fatty acid composition might vary between tissues. Because dietary fat type (especially medium-chain triglycerides (MCT)) affects tissue fatty acid composition, feeding diets with high levels of MCT had lower n3 and greater $n 6$ fatty acid levels in the neutral lipid fraction of muscle tissue [27]. Therefore, the variations in fatty acid composition might not be impacted by clofibrate only but also by diet composition. Indeed, the total fatty acid and polyunsaturated fatty acids, especially the $\mathrm{n} 6$ fatty acids, were significantly reduced in pigs who received the Tri2MPA diet in this study. This is a very interesting finding and could be due to the role of 2MPA in CAC anaplerosis. It has been reported that the monomethyl branched-chain fatty acids could be accumulated in the liver by feeding a high fat diet with protein [28], implying that 2MPA, as an anaplerotic substrate, plays a role in fatty acid metabolism.

It is remarkable that the addition of carnitine in the incubation medium significantly increased palmitic acid oxidation. Moreover, the increase in ${ }^{14} \mathrm{C}$ accumulation in ASP was much greater than in $\mathrm{CO}_{2}$, resulting in a significant change in the distribution between $\mathrm{CO}_{2}$ and ASP. These results indicate that the carnitine level in the collected kidney tissues could be a limiting factor for palmitic acid oxidation. Tissue carnitine level is closely related to the dietary carnitine intake and potential capacity of endogenous synthesis in mammals $[29,30]$. However, the contribution of carnitine from endogenous synthesis to carnitine status is not known due to a lack of data and appropriate animal models [31]. In addition to dietary intake and endogenous synthesis, the carnitine status of neonatal pigs can be affected by the maternal carnitine status. Increased tissue free and total carnitine concentrations was observed in the fetuses collected from gilts given dietary carnitine supplementation [32]. Thus, in the present study, deficient carnitine in the kidney tissues collected might be related to the carnitine levels in the milk replacer and potential carnitine status at birth. Furthermore, the high percentage of ASP noticed in in vitro palmitic acid oxidation suggested that carnitine availability is essential for maintaining an active lipid metabolism, because the potential toxic coenzyme A esters can be removed by forming acylcarnitines, resulting in an increase in percentage of ASP during the fatty acid oxidation. The buffer function of carnitine in the cellular acyl-coenzyme A/coenzyme A ratio plays a critical role in normal metabolic functioning $[33,34]$.

\section{Materials and Methods}

\subsection{Animals}

A total of 72 suckled newborn pigs (male and females removed from their mothers within $6 \mathrm{~h}$ after birth, average body weight $1.31 \pm 0.027 \mathrm{~kg}$ ) from eight litters were used in this experiment. Eight pigs (one from each litter) were euthanized at birth by being sedated with isoflurane followed by exsanguination. The kidneys were removed, and weight was recorded immediately. Kidney tissue samples were collected and stored at $-80{ }^{\circ} \mathrm{C}$ for subsequent analyses. All other pigs were housed individually in a specialized intensive care nursery at $30^{\circ} \mathrm{C}$. Pigs were blocked by litter and assigned randomly into eight treatments according to a 2 (control vs. clofibrate) $\times 4$ (diets supplemented with either succinate, valerate, hexanoate, or 2MPA) factorial design. Each group was fed a basal milk replacer containing either 0 or $0.35 \%$ of the clofibrate ( $\%$ of the milk dry matter) with the supplementations of $5 \%$ glycerol + succinate (GlySuc), triglycerides of valeric acid (TriC5), hexanoic acid (TriC6), or 2-MPA (Tri2MPA). The basal milk replacer was formulated with soybean oil as a fat source with a total of $25 \%$ fat, $31 \%$ crude protein, and $36 \%$ lactose. The formulated basal milk replacer contained $12.8 \%$ of dry matter. Based on our previous study [15], the average clofibrate intake would be $\sim 200 \mathrm{mg} / \mathrm{kg}$ body weight per day if the average milk intake was $750 \mathrm{~mL}$ and the average body weight was $1.65 \mathrm{~kg}$ throughout the experimental period. Supplements to the basal diet were offset by reductions in soybean oil so that diets remained iso-caloric. The TriC5, TriC6, and Tri2MPA were synthesized in our laboratory as previously described [35]. A gravity feeding system was used to allow for the accurate measurement of milk consumption [36]. Fresh milk was provided three times per day, and diets were prepared at the arrival of each litter and stored under refrigeration. Body weight was 
recorded daily. Pigs were euthanized as newborn pigs on day 5 and tissues were collected and stored as previously described. All experimental procedures were approved by the North Carolina State University animal care and use committee (IACUC id 16-142, approved on 14 September 2016).

\subsection{Fatty Acid Oxidation Measurement In Vitro}

Palmitate oxidation was measured in fresh kidney homogenates as previously described [15]. Measurements were conducted using $\left[1-{ }^{14} \mathrm{C}\right]$ palmitic acid $(0.5 \mathrm{mM}, 0.28 \mathrm{kBq} / \mu \mathrm{mol})$ pre-incubated with or without carnitine $(1 \mathrm{mM}), \mathrm{L} 659699(1.6 \mu \mathrm{M})$, an inhibitor of both mitochondrial HMGCS and cytosolic HMGCS [37], or iodoacetamide $(50 \mu \mathrm{M})$, an inhibitor of acetoacetyl-CoA deacylase (AACD) for acetoacetate synthesis [38]. Oxidative metabolites $\left({ }^{14} \mathrm{CO}_{2}\right.$ and $\left.{ }^{14} \mathrm{C}-\mathrm{ASP}\right)$ were determined using liquid scintillation counting [14].

\subsection{Metabolite Assays}

Fatty acids were methylated using the method described by Walter et al. [39], and the fatty acid methyl esters were quantified using GC/MS (Agilent Technologies, Wilmington, DE, USA). Ketone bodies were determined using EnzyChromTM Ketone Body Assay Kit (EKBD-100) purchased from BioAssay Systems (Hayward, CA, USA), and acetate was determined using an acetate colorimetric kit from BioVision (Milpitas, CA, USA).

\subsection{Enzyme Assays}

Citrate synthase activity in mitochondria was measured with a kit purchased from Sigma-Aldrich (MAK193; St. Louis, MO, USA). The activities of acetyl-CoA and propionyl-CoA carboxylases were measured following the method described by Hugler et al. [40] with a slight modification. Briefly, homogenates from frozen tissues $(0.5-0.65 \mathrm{mg}$ protein) were incubated with acetyl-CoA or propionyl-CoA $(0.4 \mathrm{mM})$ and $\left[{ }^{14} \mathrm{C}^{-N_{2}} \mathrm{CO}_{3}(37 \mathrm{kBq} / \mu \mathrm{mol})\right.$ in a buffer containing $100 \mathrm{mM} \mathrm{Tris} / \mathrm{HCl}, \mathrm{pH}$ $7.8,5 \mathrm{mM} \mathrm{MgCl}_{2}, 5 \mathrm{mM}$ dithioerythritol, $4 \mathrm{mM} \mathrm{ATP}, 2 \mathrm{mM} \mathrm{NADPH}$, and $10 \mathrm{mM} \mathrm{NaHCO}_{3}$ at $37^{\circ} \mathrm{C}$ for $6 \mathrm{~min}$. The reaction was started by adding the substrate (acetyl-CoA or propionyl-CoA) and ended by adding $\mathrm{HCl}$. The unused substrate then was removed from the reactant using an analytical evaporator (MULTVAP, Berlin, MA, USA) under $\mathrm{N}_{2}$.

\subsection{Gene Expression}

To test the effect of clofibrate on fatty acid metabolism in neonatal kidney, kidney samples were snap frozen in liquid nitrogen for analyzing mRNA abundance of peroxisome proliferator-activated receptor $\alpha(P P A R \alpha)$, malonyl-CoA decarboxylase $(M C D)$, 3-ketoacyl-CoA thiolase $(K-C o A)$, fibroblast growth factor 21 (FGF21), peroxisome proliferator-activated receptor $\gamma$ coactivator-1 $\alpha$ (PGC1 $\alpha$ ), medium-chain acyl-CoA dehydrogenase (MCAD) and long-chain acyl-CoA dehydrogenase (LCAD), and very long-chain acyl-CoA dehydrogenase $(V L C A D)$ via qPCR. Guanidine isothiocynate was used for total RNA extraction. The extracted mRNA was quantified with spectrophotometry (NanoDrop, Thermo Scientific, Wilmington, DE, USA) and treated with Turbo DNase (Ambion, Austin, TX, USA). The treated mRNA then was transcribed using an iScripTM Select cDNA synthesis kit (Bio-Rad Laboratories, Hercules, CA, USA). Primers were designed based on the use of GenBank, as described previously (Table S2, [14]). The mRNA abundances were measured with MyiQ Single Color RT-PCR (Bio-Rad Laboratories, Hercules, CA, USA).

\subsection{Chemicals}

Palmitic acid $\left[1-{ }^{14} \mathrm{C}\right]$ and sodium bicarbonate $\left[{ }^{14} \mathrm{C}\right]$ were purchased from American Radiolabeled Chemicals, Inc. (Saint Louis, MO, USA). L659699 was purchased from Cayman Chemical (Ann Arbor, MI 48108, USA), clofibrate was purchased from TCI America (Portland, OR, USA), and all other chemicals were purchased from Sigma-Aldrich (Saint Louis, MO, USA). 


\subsection{Statistical Analysis}

Data from enzyme assays was subjected to ANOVA according to a $2 \times 4$ factorial randomized complete block design using the general linear models (GLM) procedure of SAS (SAS software 9.3, Cary, NC, USA). Data from in vitro fatty acid oxidative measurements of $5 \mathrm{~d}$-old pigs were subjected to ANOVA according to split-plot design, using the GLM procedure of SAS. The main plot was the eight dietary treatments on animals and the sub-plot was the four treatments on the tissues (with or without carnitine, L659699, and iodoacetamide). Data from the $5 \mathrm{~d}$-old pigs were compared to the data from newborns also using ANOVA according a randomized completed design with pre-planned contrasts. Animal replication was projected using power tests employing data (means and stdev) from our previous studies [14,41] and the power for two-tail at $>0.9$. When the interactions between clofibrate and dietary medium-chain fatty acid treatments (main dietary factors) or the main dietary factors and in vitro treatments were not statistically significant, we presented the results based on the significant effects of the main factors only. All values are presented as least squares means \pm SEM. Differences were declared at a $p$-value of $\leq 0.05$.

\section{Conclusions}

Clofibrate induces fatty acid oxidation and alters renal fatty acid composition. Dietary supplementation of MCFA as anaplerotic and ketogenic carbon sources may modify the metabolic pathways of renal fatty acid oxidation, but the modification is minimal and has no effect on the elevated fatty acid oxidation induced by activation of PPAR $\alpha$ at current status. The renal ketogenic capacity is low in piglets, and the simulative effect from TriC6 may be due to acetogenesis, the predominate pathway for releasing the CoA from acetyl-CoA generated from $\beta$-oxidation. The role of carnitine in kidney is essential and merits further investigation in neonatal pigs.

Supplementary Materials: Supplementary materials can be found at http://www.mdpi.com/1422-0067/21/3/726/s1.

Author Contributions: Project administration and supervision X.L.; investigation, X.L. and J.O.; methodology and formal analysis, X.L, B.P., J.Z., Y.F., Y.Z. (Yongwen Zhu), Y.Z. (Yong Zhang), and F.W.; data curation, X.L.; writing-original draft preparation, X.L.; writing-review and editing, X.L., B.P., and J.O; funding acquisition, X.L. and J.O. All authors have read and agreed to the published version of the manuscript.

Funding: This work is supported by AAnimal Nutrition, Growth and Lactation] [grant no. 2015-67015-23245 /project accession no. 1005855] from the USDA National Institute of Food and Agriculture, and by the North Carolina Agricultural Research Service. Funds received from the grants cover the costs to publish this article in open access.

Acknowledgments: Authors wish to express thanks to Sean Sabin, Zoe Olmsted, Megan M. Wallace, and Bryanna Gristina for help with animal feeding, sample collection, and fatty acid analysis.

Conflicts of Interest: The authors declare no conflict of interest. The funders had no role in the design of the study; in the collection, analyses, or interpretation of data; in the writing of the manuscript, or in the decision to publish the results.

\section{Abbreviations}

$\begin{array}{ll}\text { CAC } & \text { Citric acid cycle } \\ \text { GlySuc } & \text { Glycerol-succinate } \\ \text { TriC5 } & \text { Triglycerides of valeric acid } \\ \text { TriC6 } & \text { Triglycerides of hexanoic acid } \\ \text { TriMPA } & \text { Triglycerides of 2-methylpentonoic acid } \\ \text { ASP } & \text { Acid soluble products } \\ \text { PPAR } \alpha & \text { Peroxisome proliferator-activated receptor } \alpha \\ \text { CKD } & \text { Chronic kidney disease } \\ \text { mHMGCS } & \text { Mitochondrial 3-hydroxy-3-methyl-glutaryl-CoA synthase } \\ \text { MCFA } & \text { Medium-chain fatty acids } \\ \text { AACD } & \text { Acetoacetyl-CoA deacylase }\end{array}$




\section{References}

1. Takahashi, K.; Kamijo, Y.; Hora, K.; Hashimoto, K.; Higuchi, M.; Nakajima, T.; Ehara, T.; Shigematsu, H.; Gonzalez, F.J.; Aoyama, T. Pretreatment by low-dose fibrates protects against acute free fatty acid-induced renal tubule toxicity by counteracting PPAR $\alpha$ deterioration. Toxicol. Appl. Pharmacol. 2011, 252, $237-249$. [CrossRef] [PubMed]

2. Muroya, Y.; Ito, O. Effect of clofibrate on fatty acid metabolism in the kidney of puromycin-induced nephrotic rats. Clin. Exp. Nephrol. 2016, 20, 862-870. [CrossRef] [PubMed]

3. Chuppa, S.; Liang, M.; Liu, P.; Liu, Y.; Casati, M.C.; Cowley, A.W.; Patullo, L.; Kriegel, A.J. MicroRNA-21 regulates peroxisome proliferator-activated receptor alpha, a molecular mechanism of cardiac pathology in Cardiorenal Syndrome Type 4. Kidney Int. 2018, 93, 375-389. [CrossRef] [PubMed]

4. Fall, C.H. Fetal malnutrition and long-term outcomes. Nestle Nutr. Inst. Workshop Ser. 2013, 74, 11-25.

5. Sampaio, L.S.; da Silva, P.A.; Ribeiro, V.S.; Castro-Chaves, C.; Lara, L.S.; Vieyra, A.; Einicker-Lamas, M. Bioactive lipids are altered in the kidney of chronic undernourished rats: Is there any correlation with the progression of prevalent nephropathies? Lipids Health Dis. 2017, 16, 245. [CrossRef]

6. Drożdż, D.; Kwinta, P.; Sztefko, K.; Kordon, Z.; Drożdż, T.; Łatka, M.; Miklaszewska, M.; Zachwieja, K.; Rudziński, A.; Pietrzyk, J.A. Oxidative Stress Biomarkers and Left Ventricular Hypertrophy in Children with Chronic Kidney Disease. Oxid. Med. Cell Longev. 2016, 2016, 7520231. [CrossRef]

7. Portilla, D.; Dai, G.; Peters, J.M.; Gonzalez, F.J.; Crew, M.D.; Proia, A.D. Etomoxir-induced PPARalpha-modulated enzymes protect during acute renal failure. Am. J. Physiol. Renal Physiol. 2000, 278, F667-F675. [CrossRef]

8. Veerkamp, J.H.; van Moerkerk, H.T. Peroxisomal fatty acid oxidation in rat and human tissues. Effect of nutritional state, clofibrate treatment and postnatal development in the rat. Biochim. Biophys. Acta 1986, 875, 301-310. [CrossRef]

9. Ouali, F.; Djouadi, F.; Merlet-Bénichou, C.; Bastin, J. Dietary lipids regulate beta-oxidation enzyme gene expression in the developing rat kidney. Am. J. Physiol. 1998, 275, F777-F784.

10. Vamecq, J.; Draye, J.P. Pathophysiology of peroxisomal beta-oxidation. Essays Biochem. 1989, 24, 115-225.

11. Palmer, C.N.; Hsu, M.H.; Griffin, K.J.; Raucy, J.L.; Johnson, E.F. Peroxisome proliferator activated receptor-alpha expression in human liver. Mol. Pharmacol. 1998, 53, 14-22. [CrossRef] [PubMed]

12. Odle, J.; Lin, X.; Jacobi, S.K.; Kim, S.W.; Stahl, C.H. The suckling piglet as an agrimedical model for the study of pediatric nutrition and metabolism. Annu. Rev. Anim. Biosci. 2014, 2, 419-444. [CrossRef] [PubMed]

13. He, Y.; Khan, I.; Bai, X.; Odle, J.; Xi, L. Activation of PPAR $\alpha$ by Oral Clofibrate Increases Renal Fatty Acid Oxidation in Developing Pigs. Int. J. Mol. Sci. 2017, 18, 2663. [CrossRef] [PubMed]

14. Lin, X.; Shim, K.; Odle, J. Carnitine palmitoyltransferase I control of acetogenesis, the major pathway of fatty acid \{beta\}-oxidation in liver of neonatal swine. Am. J. Physiol. Regul. Integr. Comp. Physiol. 2010, 298, R1435-R1443. [CrossRef] [PubMed]

15. Shim, K.; Jacobi, S.; Odle, J.; Lin, X. Pharmacologic activation of peroxisome proliferator-activating receptor- $\alpha$ accelerates hepatic fatty acid oxidation in neonatal pigs. Oncotarget 2018, 9, 23900-23914. [CrossRef]

16. Courchesne-Loyer, A.; Fortier, M.; Tremblay-Mercier, J.; Chouinard-Watkins, R.; Roy, M.; Nugent, S.; Castellano, C.A.; Cunnane, S.C. Stimulation of mild, sustained ketonemia by medium-chain triacylglycerols in healthy humans: Estimated potential contribution to brain energy metabolism. Nutrition 2013, 29, 635-640. [CrossRef]

17. Lowe, D.M.; Tubbs, P.K. Succinylation and inactivation of 3-hydroxy-3-methylglutaryl-CoA synthase by succinyl-CoA and its possible relevance to the control of ketogenesis. Biochem. J. 1985, 232, 37-42. [CrossRef]

18. Freund, N.; Sedraoui, M.; Geloso, J.P. Fatty acid oxidation by developing rat kidney. Biol. Neonate. 1984, 45, 183-187. [CrossRef]

19. Bai, X.; Lin, X.; Drayton, J.; Liu, Y.; Ji, C.; Odle, J. Clofibrate increases long-chain fatty acid oxidation by neonatal pigs. J. Nutr. 2014, 144, 1688-1693. [CrossRef]

20. Adams, S.H.; Alho, C.S.; Asins, G.; Hegardt, F.G.; Marrero, P.F. Gene expression of mitochondrial 3-hydroxy-3-methylglutaryl-CoA synthase in a poorly ketogenic mammal: Effect of starvation during the neonatal period of the piglet. Biochem. J. 1997, 324, 65-73. [CrossRef] 
21. Odle, J. New insights into the utilization of medium-chain triglycerides by the neonate: Observations from a piglet model. J. Nutr. 1997, 127, 1061-1067. [CrossRef]

22. Owen, O.E.; Felig, P.; Morgan, A.P.; Wahren, J.; Cahill, G.F., Jr. Liver and kidney metabolism during prolonged starvation. J. Clin. Investig. 1969, 48, 574-583. [CrossRef] [PubMed]

23. Owen, O.E.; Smalley, K.J.; D'Alessio, D.A.; Mozzoli, M.A.; Dawson, E.K. Protein, fat, and carbohydrate requirements during starvation: Anaplerosis and cataplerosis. Am. J. Clin. Nutr. 1998, 68, 12-34. [CrossRef] [PubMed]

24. Owen, O.E.; Kalhan, S.C.; Hanson, R.W. The key role of anaplerosis and cataplerosis for citric acid cycle function. J. Biol. Chem. 2002, 277, 30409-30412. [CrossRef] [PubMed]

25. Reszko, A.E.; Kasumov, T.; Pierce, B.A.; David, F.; Hoppel, C.L.; Stanley, W.C.; Des Rosiers, C.; Brunengraber, H. Assessing the reversibility of the anaplerotic reactions of the propionyl-CoA pathway in heart and liver. J. Biol. Chem. 2003, 278, 34959-34965. [CrossRef]

26. Tian, Q.; Grzemski, F.A.; Panagiotopoulos, S.; Ahokas, J.T. Peroxisome proliferator-activated receptor alpha agonist, clofibrate, has profound influence on myocardial fatty acid composition. Chem. Biol. Interact. 2006, 160, 241-251. [CrossRef]

27. Craig, S.R.; Gatlin, D.M. 3rd. Coconut oil and beef tallow, but not tricaprylin, can replace menhaden oil in the diet of red drum (Sciaenops ocellatus) without adversely affecting growth or fatty acid composition. J. Nutr. 1995, 125, 3041-3048.

28. Garcia Caraballo, S.C.; Comhair, T.M.; Houten, S.M.; Dejong, C.H.; Lamers, W.H.; Koehler, S.E. High-protein diets prevent steatosis and induce hepatic accumulation of monomethyl branched-chain fatty acids. J. Nutr. Biochem. 2014, 25, 1263-1274. [CrossRef]

29. Fischer, M.; Varady, J.; Hirche, F.; Kluge, H.; Eder, K. Supplementation of L-carnitine in pigs: Absorption of carnitine and effect on plasma and tissue carnitine concentrations. Arch. Anim. Nutr. 2009, 63, 1-15. [CrossRef]

30. Broderick, T.L.; Cusimano, F.A.; Carlson, C.; Tamura, L.K. Acute Exercise Stimulates Carnitine Biosynthesis and OCTN2 Expression in Mouse Kidney. Kidney Blood Press Res. 2017, 42, 398-405. [CrossRef]

31. Ringseis, R.; Keller, J.; Eder, K. Basic mechanisms of the regulation of L-carnitine status in monogastrics and efficacy of L-carnitine as a feed additive in pigs and poultry. J. Anim. Physiol. Anim. Nutr. 2018, 102, 1686-1719. [CrossRef] [PubMed]

32. Brown, K.R.; Goodband, R.D.; Tokach, M.D.; Dritz, S.S.; Nelssen, J.L.; Minton, J.E.; Higgins, J.J.; Lin, X.; Odle, J.; Woodworth, J.C.; et al. Effects of feeding L-carnitine to gilts through day 70 of gestation on litter traits and the expression of insulin-like growth factor system components and L-carnitine concentration in foetal tissues. J. Anim. Physiol. Anim. Nutr. 2008, 92, 660-667. [CrossRef] [PubMed]

33. Van Kempen, T.A.; Odle, J. Medium-chain fatty acid oxidation in colostrum-deprived newborn piglets: Stimulative effect of L-carnitine supplementation. J. Nutr. 1993, 123, 1531-1537. [CrossRef] [PubMed]

34. Marín, V.B.; Azocar, M.; Molina, M.; Guerrero, J.L.; Ratner, R.; Cano, F. Total carnitine and acylated carnitine ratio: Relationship of free carnitine with lipid parameters in pediatric dialysis patients. Adv. Perit. Dial. 2006, 22, 130-135. [PubMed]

35. Heo, K.N.; Lin, X.; Han, I.K.; Odle, J. Medium-chain fatty acids but not L-carnitine accelerate the kinetics of $\left[{ }^{14} \mathrm{C}\right]$ triacylglycerol utilization by colostrum-deprived newborn pigs. J. Nutr. 2002, 132, 1989-1994. [CrossRef] [PubMed]

36. Corl, B.A.; Mathews Oliver, S.A.; Lin, X.; Oliver, W.T.; Ma, Y.; Harrell, R.J.; Odle, J. Conjugated linoleic acid reduces body fat accretion and lipogenic gene expression in neonatal pigs fed low- or high-fat formulas. J. Nutr. 2008, 138, 449-454. [CrossRef]

37. Greenspan, M.D.; Yudkovitz, J.B.; Lo, C.Y.; Chen, J.S.; Alberts, A.W.; Hunt, V.M.; Chang, M.N.; Yang, S.S.; Thompson, K.L.; Chiang, Y.C. Inhibition of hydroxymethylglutaryl-coenzyme A synthase by L-659,699. Proc. Natl. Acad. Sci. USA 1987, 84, 7488-7492. [CrossRef]

38. Burch, R.E.; Wertheim, A.R. Subcellular localization of acetoacetyl-CoA deacylase and its role in acetoacetate synthesis. Am. J. Clin. Nutr. 1973, 26, 814-822. [CrossRef]

39. Walter, K.R.; Lin, X.; Jacobi, S.K.; Käser, T.; Esposito, D.; Odle, J. Dietary arachidonate in milk replacer triggers dual benefits of PGE2 signaling in LPS-challenged piglet alveolar macrophages. J. Anim. Sci. Biotechnol. 2019. [CrossRef] 
40. Hügler, M.; Krieger, R.S.; Jahn, M.; Fuchs, G. Characterization of acetyl-CoA/propionyl-CoA carboxylase in Metallosphaera sedula. Carboxylating enzyme in the 3-hydroxypropionate cycle for autotrophic carbon fixation. Eur. J. Biochem. 2003, 270, 736-744. [CrossRef]

41. Peffer, P.L.; Lin, X.; Odle, J. Hepatic beta-oxidation and carnitine palmitoyltransferase I in neonatal pigs after dietary treatments of clofibric acid, isoproterenol, and medium-chain triglycerides. Am. J. Physiol. Regul. Integr. Comp. Physiol. 2005, 288, R1518-R1524. [CrossRef] [PubMed]

(C) 2020 by the authors. Licensee MDPI, Basel, Switzerland. This article is an open access article distributed under the terms and conditions of the Creative Commons Attribution (CC BY) license (http://creativecommons.org/licenses/by/4.0/). 